\title{
Trichinellosis in hospitalized patients from Western Romania: A retrospective study
}

\author{
MARIA ALINA LUPU ${ }^{1,2^{*}}$, RADU PAVEL $^{3 *}$, VOICHITA ELENA LAZUREANU $^{4}$, \\ EMILIAN DAMIAN POPOVICI ${ }^{3}$ and TUDOR RARES OLARIU ${ }^{1,2}$
}

\author{
${ }^{1}$ Department of Infectious Diseases-Parasitology, ${ }^{2}$ Center for Diagnosis and Study of Parasitic Diseases, \\ Departments of ${ }^{3}$ Infectious Diseases-Epidemiology and ${ }^{4}$ Infectious Diseases-Infectious Diseases, \\ 'Victor Babeș' University of Medicine and Pharmacy of Timisoara, 300041 Timisoara, Romania
}

Received April 19, 2021; Accepted May 19, 2021

DOI: $10.3892 / \mathrm{etm} .2021 .10327$

\begin{abstract}
Trichinellosis is a public health problem and an economic issue in porcine animal production and food safety. The aim of this retrospective study was to evaluate the current epidemiologic, laboratory, clinical and therapeutic aspects of human trichinellosis in Western Romania. We retrospectively investigated the medical records of patients hospitalized in infectious diseases hospitals from three counties in Western Romania, between January 1st, 2012 and December 31st, 2016. A total of 83 patients diagnosed with trichinellosis were included in the study. Pork meat was the food source of infection in $76(91.6 \%)$ patients and wild boar meat in $4(4.8 \%)$. Patients were aged between 2 and 78 years; 48 (57.8\%) were males and 27 (32.5\%) came from an urban area. The most frequent symptoms included myalgia in $66(79.5 \%)$ patients, fever in $55(66.3 \%)$, eyelid edema in $40(48.2 \%)$ and asthenia in $35(42.2 \%)$. Two patients died and the others had favorable outcome. Although the number of reported cases has decreased in the past years, trichinellosis remains an important public health problem in Western Romania. Educational programs for both swine breeders and consumers are imperative, and implementation of strict hygienic measures aimed to control infection transmission are strongly recommended.
\end{abstract}

\section{Introduction}

Trichinellosis is a foodborne parasitic disease with worldwide distribution (1) that can cause acute and chronic illness (2).

Correspondence to: Dr Maria Alina Lupu or Professor Tudor Rareș Olariu, Department of Infectious Diseases-Parasitology, 'Victor Babeș' University of Medicine and Pharmacy of Timisoara, Sq. Eftimie Murgu 1, 300041 Timisoara, Romania

E-mail: mariaalinalupu@gmail.com

E-mail:rolariu@yahoo.com

*Contributed equally

Key words: epidemiology, Western Romania, trichinellosis, zoonosis, hospitalized patients
This zoonosis is a public health problem by affecting human patients and an economic issue in porcine animal production and food safety (3).

Trichinella infection in humans can be divided into two phases: An intestinal (enteral) phase and a muscular (systemic) phase (3). The symptoms are highly correlated with the stage of the infection (4) and the severity of clinical symptoms are directly correlated with the number of larvae ingested (3) and with the number of larvae produced by adult worms in the small intestine (5). Therefore, symptoms may range from mild transient diarrhea, nausea, upper abdominal pain, vomiting (can appear approximately 2 days post infection) followed by myalgia, periorbital and/or facial edema, conjunctivitis, fever, headache, skin rash $(3,4)$ to complications such as myocarditis and encephalitis (6). Despite therapy, lethality in severe cases has been reported at a rate of up to $5 \%$ (3).

To ensure food safety for consumers, the European Commission (EC) legislation requires mandatory meat inspection for farmed and wild animal species slaughtered for consumption (e.g., domestic pigs, horses and wild boar) (3).

Romania, the largest southeast European country, has reported the highest number of human trichinellosis cases in the European Union since 2007 (7,8). The aim of this study was to evaluate the current epidemiological, laboratory, clinical and therapeutic aspects of human trichinellosis in Western Romania, addressing the question of whether this zoonosis is still an important health problem in this well-known Romanian endemic region.

\section{Patients and methods}

This retrospective study was conducted in 2 phases and included 83 consecutive patients diagnosed and hospitalized with trichinellosis in Western Romania between January 1st, 2012 and December 31st, 2016 in three counties located in Western Romania (Timis County, Arad County and Hunedoara County) with a total population of 1,532,734. In the first phase, we investigated the clinical database in a major infectious disease hospital from Timis County, between January 1st, 2012 and June 30th, 2016. Twenty-three patients were diagnosed and hospitalized with trichinellosis (9). In the second phase we extended the studied period (between January 1st, 2012 and 
December 31st, 2016) and the research area with two more counties in Western Romania (Arad County and Hunedoara County). Another 60 patients were identified. Medical records of the patients diagnosed with trichinellosis were reviewed. From the medical records we collected data regarding age, sex, environment, clinical symptomatology, length of hospital stay, laboratory investigation results (leukocyte and eosinophil count, erythrocyte sedimentation rate, serologic testing for Trichinella) and specific therapy. According to the medical records, the diagnosis was established based on history, clinical symptoms, Trichinella-specific antibody response (ELISA), detection of Trichinella larvae (in patient muscle biopsy and/or in the food item) and epidemiological links (exposure to a common source or contaminated meat) (10). Individuals were grouped in two age categories, older and younger than 15 years of age (Table I).

Data were compiled in a Microsoft Excel database, version 2011 (Microsoft Corp.). Statistical analysis was performed using Epi Info Version 7.2 (CDC). Bartlett's Test was used to determine whether the variables were distributed normally. Descriptive statistics (mean, standard deviation, percentage, median and interquartile range) were calculated as appropriate. Student's t-test and Fisher exact test were used to evaluate differences between the studied groups. Mann-Whitney $U$ test was used for non-parametric distribution. A probability level of $\mathrm{P}<0.05$ was considered to indicate statistical significance.

This study was approved by each of the infectious disease hospital's ethics committee: 'Victor Babes' Infectious Diseases Hospital Timisoara, Timis County; Infectious Disease Hospital Arad, Arad County; Municipal Hospital 'Doctor Alexandru Simionescu' Hunedoara, Hunedoara County.

\section{Results}

Eighty-three patients were diagnosed and hospitalized with trichinellosis in Western Romania. Patients were aged between 2 and 78 years (mean age, 35.9); 57.8\% (48/83) were males and $32.5 \%(27 / 83)$ were inhabitants of urban areas. The majority of patients were aged over 15 years [88\% (73/83)] (Table I). The patients were residents of Arad $(n=43 ; 51.8 \%)$, Timis $(n=14 ; 16.9 \%)$ and Hunedoara $(n=26 ; 31.3 \%)$ counties (Fig. 1). The incidence (cases per 100,000 inhabitants) for the studied period was 9.98 in Arad, 2.04 in Timis and 6.21 in Hunedoara.

The most frequent symptoms included: myalgia in 66 $(79.5 \%)$, fever in $55(66.3 \%)$, eyelid edema in $40(48.2 \%)$ and asthenia in 35 (42.2\%). Other clinical findings included headache, diarrhea, abdominal pain and cutaneous rash (Table II). Clinical signs were reported 1 to 30 days (average incubation period was 7.6 days) after eating contaminated meat (raw pork products from domestic pigs raised and slaughtered in their own backyard and/or wild boar from noncommercial sources). Sixty-eight $(81.9 \%)$ patients presented symptoms in the first 10 days.

Hospitalization period ranged between 1 and 17 days (average, 7.5 days). In 22 (26.5\%) patients, this period ranged between 10 and 17 days and required significant health care resources.

Of the 83 patients, $43(51.8 \%)$ had high levels of white blood cells (more than $10,000 / \mathrm{mm}^{3}$ ). The mean value of the leukocyte count was higher in patients aged over 15 years than in patients aged below 15 years $(\mathrm{P}=0.070)$. Seventy-six $(91.6 \%)$ patients had eosinophilia more than $5 \%$. The mean value of the eosinophil count was significantly higher in patients aged over 15 years compared to patients aged below 15 years $(\mathrm{P}=0.003)$. The median erythrocyte sedimentation rate (ESR) value was significantly higher in patients aged over 15 years compared to patients aged below 15 years $(\mathrm{P}=0.020$; Table III). Sixty-four patients $(77.1 \%)$ had ESR higher than $10 \mathrm{~mm} / \mathrm{h}$.

Sixty-nine patients $(83.1 \%)$ received treatment with albendazole, 14 (16.9\%) with mebendazole and 47 (56.6\%) patients received associated corticotherapy. Seven patients continued antiparasitic treatment after discharge between 2 and 13 days.

Of the 83 patients included in the study, one male patient maintained his motor deficit on the left side after discharge and two patients with neurological complications (stroke, right hemiplegia) died. The other patients had favorable outcome.

Over a 5-year period, the year with the highest reported number of trichinellosis cases was 2014 (41/83, 49.4\%) (Table II). November was the month with the highest reported rate, with $32(38.6 \%)$ cases, followed by January with 26 (31.3\%), December with 9 (10.8\%), April with 6 (7.2\%), May with $3(3.6 \%)$, February and March with 2 (2.4\%), June, August and September with one case $(1.2 \%)$.

Seventy-five patients from 10 different family outbreaks met the epidemiological criteria of exposure to a common source of infection. Five of these patients were from three family outbreaks and met the epidemiological criteria of exposure to confirmed contaminated meat products (traced back to trichinelloscopy-positive meat). Eight patients were sporadic cases. Eleven patients from 5 different family outbreaks and one sporadic case were tested for Trichinella-specific antibody response (ELISA) and 8 had positive results. Patients who had negative results met the epidemiological criteria for diagnosis. Two sporadic cases were confirmed by muscle biopsy (Table IV).

Overall 73 patients were classified as probable cases and 10 were classified as confirmed cases.

Pork meat products from privately raised animals were consumed in $76(91.6 \%)$ patients and wild boar meat products from noncommercial sources in $4(4.8 \%)$; these 4 patients were all hospitalized in 2012 and were residents of Timis county. The proportion of pork meat products as food source cases was significantly higher in patients with exposure to a common source (epidemiological links) [odds ratio $(\mathrm{OR})=10.6$; $95 \%$ confidence interval $(\mathrm{CI}), 1.85-61.3 ; \mathrm{P}=0.01]$.

\section{Discussion}

Modern pork production systems and slaughter inspection programs have reduced or eliminated pork as a source for trichinellosis in many European Union (EU) countries (1). In the EU, most pigs are subject to official meat inspection at slaughter in accordance with Regulation (EC) No 2015/1375; only pigs slaughtered for own consumption are not covered by this regulation (11).

The number of cases and the EU notification rate have been steadily decreasing since 2012, and in 2016 the lowest rate $(0.02)$ was reported since the beginning of the EU-level surveillance. The decrease was mainly due to a markedly 
Table I. Distribution of trichinellosis cases in Western Romania by age categories, sex and area of residence ( $\mathrm{n}=83$ ).

\begin{tabular}{|c|c|c|c|c|c|}
\hline \multirow[b]{2}{*}{ Age categories } & \multirow[b]{2}{*}{ No. of cases $(\%)$} & \multicolumn{2}{|c|}{ Sex } & \multicolumn{2}{|c|}{ Area of residence } \\
\hline & & Male & Female & Urban & Rural \\
\hline$<15$ years & $10(12)$ & 3 & 7 & 4 & 6 \\
\hline$>15$ years & $73(88)$ & 45 & 28 & 23 & 50 \\
\hline Total & $83(100)$ & 48 & 35 & 27 & 56 \\
\hline
\end{tabular}

The number in parentheses are the percentage of cases.

Table II. Reported clinical symptoms in patients hospitalized with trichinellosis included in the study $(n=83)$.

\begin{tabular}{lrrrrrrrrr}
\hline & \multicolumn{7}{c}{ Symptoms n $(\%)$} \\
\cline { 2 - 9 } Year & $\begin{array}{c}\text { No. of } \\
\text { cases }\end{array}$ & Myalgia & Fever & $\begin{array}{c}\text { Eyelid } \\
\text { edema }\end{array}$ & Asthenia & Headache & Diarrhea & $\begin{array}{c}\text { Abdominal } \\
\text { pain }\end{array}$ & $\begin{array}{c}\text { Cutaneous } \\
\text { rash }\end{array}$ \\
\hline 2012 & 26 & $23(88.4)$ & $19(73.1)$ & $6(23.1)$ & $6(23.8)$ & $2(7.7)$ & $8(30.7)$ & $2(7.7)$ & $5(19.2)$ \\
2013 & 2 & $2(100)$ & $1(50.0)$ & $2(100)$ & $1(50.0)$ & $2(100)$ & $0(0)$ & $0(0)$ & $0(0)$ \\
2014 & 41 & $32(78.0)$ & $23(56.1)$ & $28(68.3)$ & $24(58.5)$ & $16(39.0)$ & $11(26.8)$ & $2(4.9)$ & $1(2.44)$ \\
2015 & 4 & $2(50.0)$ & $4(100)$ & $1(25.0)$ & $1(25.0)$ & $3(75.0)$ & $2(50.0)$ & $0(0)$ & $0(0)$ \\
2016 & 10 & $7(70.0)$ & $8(80.0)$ & $3(30.0)$ & $3(30.0)$ & $2(20.0)$ & $1(10.0)$ & $1(10.0)$ & $1(10.0)$ \\
Total & 83 & $66(79.5)$ & $55(66.3)$ & $40(48.2)$ & $35(42.2)$ & $25(30.1)$ & $22(26.5)$ & $5(6.0)$ & $7(8.43)$ \\
\hline
\end{tabular}

The number in parentheses are the percentage of cases.

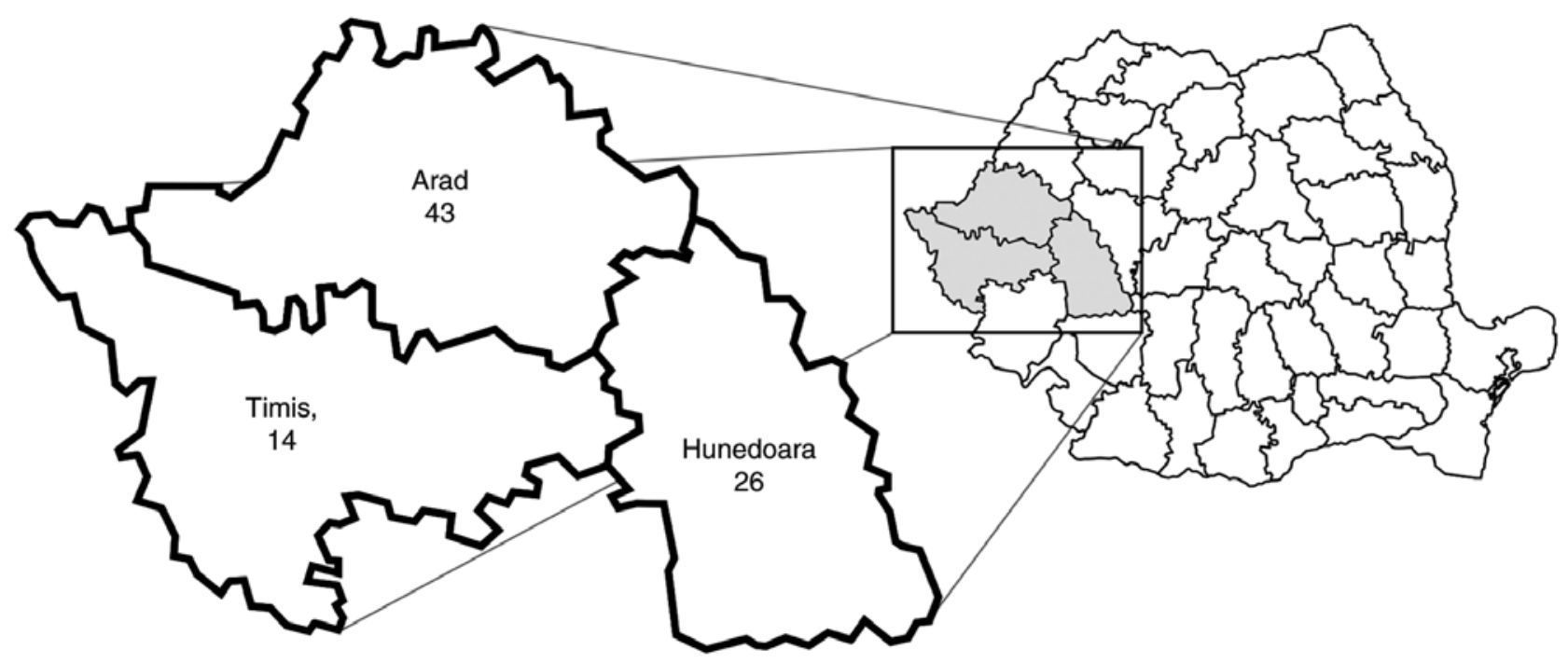

Figure 1. Distribution of trichinellosis cases by county residence in Western Romania, 2012-2016.

reduced number of trichinellosis cases reported by Bulgaria and Romania, which had experienced most Trichinella outbreaks in previous years (11). Educating consumers (eating only well-cooked meat), improvements in pig-rearing practices, and increased control measures at slaughterhouses may explain this decrease (12).

Our findings were lower than the number of trichinellosis hospitalized cases previously reported in Western
Romania: during 2007-2009, trichinellosis was diagnosed in 91 individuals from Arad $(n=49)$ and Timis $(n=42)$ counties (13); during 1996-2005, 492 patients with trichinellosis were reported in Hunedoara county alone (14). Therefore, our results suggest a decreasing trend of trichinellosis in Western Romania. However, the number of cases from Western Romania exceeded the number of confirmed cases at a national level in countries such as Belgium, Germany, 
Table III. Laboratory data in patients diagnosed with trichinellosis.

\begin{tabular}{|c|c|c|c|c|c|}
\hline \multirow{4}{*}{$\begin{array}{l}\text { Variable } \\
\text { Leukocyte count } \\
\left(\text { cells } / \mathrm{mm}^{3}\right)\end{array}$} & \multirow{4}{*}{$\begin{array}{c}\begin{array}{c}\text { Normal } \\
\text { values }\end{array} \\
4,500-9,999\end{array}$} & \multirow{4}{*}{$\begin{array}{c}\begin{array}{c}\text { Range of values } \\
(\mathrm{N}=83)\end{array} \\
4,100-45,560 \\
(12,526.8 \pm 6,941.8)^{\mathrm{a}}\end{array}$} & \multicolumn{2}{|c|}{ Age group (years) } & \multirow{4}{*}{$\frac{\text { P-value }}{0.070}$} \\
\hline & & & $<15$ & $>15$ & \\
\hline & & & \multicolumn{2}{|c|}{ Range of values } & \\
\hline & & & $\begin{array}{c}5,700-18,480 \\
(9,896 \pm 4,265.9)^{\mathrm{a}}\end{array}$ & $\begin{array}{c}4,100-45,560 \\
(12,887.3 \pm 7,177.4)^{\mathrm{a}}\end{array}$ & \\
\hline Eosinophil count (\%) & $0-4.9$ & $\begin{array}{c}0.2-69.9 \\
(21 \pm 15.9)^{\mathrm{a}}\end{array}$ & $\begin{array}{l}0.3-30.8 \\
(10 \pm 9.8)^{\mathrm{a}}\end{array}$ & $\begin{array}{c}0.2-69.9 \\
(22.5 \pm 15.9)^{\mathrm{a}}\end{array}$ & 0.003 \\
\hline $\begin{array}{l}\text { Erythrocyte sedimentation } \\
\text { rate }(\mathrm{mm} / \mathrm{h})\end{array}$ & $0-10$ & $\begin{array}{c}2-80 \\
15(10-23)^{b}\end{array}$ & $\begin{array}{c}5-26 \\
9(5-14)^{b}\end{array}$ & $\begin{array}{c}2-80 \\
15(10-23)^{b}\end{array}$ & 0.020 \\
\hline
\end{tabular}

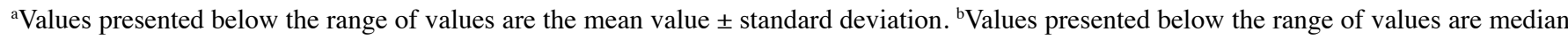
(interquartile range).

Table IV. Distribution of trichinellosis cases in Western Romania by family outbreak, county, epidemiological link, laboratory criteria and infection source $(n=83)$.

\begin{tabular}{|c|c|c|c|c|c|c|c|c|}
\hline \multirow[b]{2}{*}{$\begin{array}{l}\text { Studied } \\
\text { period }\end{array}$} & \multirow[b]{2}{*}{ County } & \multirow[b]{2}{*}{$\begin{array}{l}\text { Family } \\
\text { outbreak } \\
\text { (cases) }\end{array}$} & \multicolumn{2}{|c|}{ Epidemiological link } & \multicolumn{3}{|c|}{ Laboratory criteria } & \multirow[b]{2}{*}{$\begin{array}{l}\text { Food } \\
\text { source }\end{array}$} \\
\hline & & & $\begin{array}{c}\text { Common } \\
\text { source }\end{array}$ & $\begin{array}{l}\text { Contaminated } \\
\text { meat products } \\
\text { (trichineloscopy) }\end{array}$ & $\begin{array}{c}\text { Trichinella- } \\
\text { specific } \\
\text { antibody } \\
\text { (ELISA) }^{+}\end{array}$ & $\begin{array}{l}\text { Trichinella- } \\
\text { specific } \\
\text { antibody } \\
\text { (ELISA)- }\end{array}$ & $\begin{array}{l}\text { Muscle } \\
\text { biopsy }\end{array}$ & \\
\hline \multirow[t]{6}{*}{2012} & Timis & 4 & Yes & - & - & 2 & - & Wild boar \\
\hline & & 3 & Yes & - & 1 & - & - & Pork \\
\hline & Hunedoara & 6 & Yes & - & 1 & 1 & - & Pork \\
\hline & & 4 & Yes & - & - & - & - & Pork \\
\hline & & 8 & Yes & 2 yes & - & - & - & Pork \\
\hline & & 1 (sporadic) & - & - & - & - & - & Pork \\
\hline 2013 & Hunedoara & 2 (sporadic) & - & - & - & - & - & Pork \\
\hline \multirow[t]{4}{*}{2014} & Arad & 34 & Yes & 1 yes & 3 & - & - & Pork \\
\hline & & 1 (sporadic) & - & - & - & - & - & Unknown \\
\hline & Hunedoara & 5 & Yes & 2 yes & - & - & - & Pork \\
\hline & Timis & 1 (sporadic) & - & - & - & - & Yes & Pork \\
\hline \multirow[t]{3}{*}{2015} & Timis & 2 & Yes & - & 2 & - & - & Pork \\
\hline & Arad & 1 (sporadic) & - & - & & - & Yes & Unknown \\
\hline & & 1 (sporadic) & - & - & 1 & - & - & Unknown \\
\hline \multirow[t]{3}{*}{2016} & Timis & 3 & Yes & - & - & - & - & Pork \\
\hline & & 1 (sporadic) & - & - & - & - & - & Pork \\
\hline & Arad & 6 & Yes & - & - & - & - & Pork \\
\hline
\end{tabular}

ELISA, enzyme-linked immunosorbent assay.

Latvia, Lithuania, Poland and Spain according to the ECDC database (7).

Prevention and control of trichinellosis is a matter of education and hygiene in the environment and at home (2). Of the 83 patients with trichinellosis, 10 (12\%) were aged below 15 years. This suggests a lack of education in parents (15). Western Romania was part of the Austrian-Hungarian empire until 1918 and populations living in this area may have maintained various customs and food habits even today (raw meat products consumption), which are known to be risk factors for trichinellosis (16).

Generally, traditional pork products made with the infected meat are often given as gifts to relatives or friends residing in urban regions, because there is a preference for home-made products over commercially processed meat products and often cause small and clustered outbreaks in Trichinella-endemic 
regions. Frequently, people from urban areas buy their own pigs, which are raised and slaughtered by their friends or relatives in the countryside (13). Between 1998 and 2011, in Western Romania, the annual average number of infected pigs on farms was 48.6 and in private households 29.1 (17).

No species identification of Trichinella was carried out in this study. We focused on the epidemiological aspects of trichinellosis in Western Romania based on the available information collected from the patient medical records.

Trichinellosis can be a serious human disease, particularly in elderly individuals, in whom severe complications such as myocarditis or encephalitis can lead to death (18).

In Romania, trichinellosis may not be diagnosed and reported unless infection is sufficiently severe to require hospitalization or the cases are part of a larger outbreak that requires attention from Public Health Authorities (19). It is highly likely that the true prevalence of human trichinellosis in Romania is higher than the reported cases, due to multiple causes. Asymptomatic and subclinical infections may be undiagnosed. Consequently, they are not usually officially recorded as having trichinellosis (19).

Public health strategies should be maintained and permanently improved. Good management practices that eliminate the risk of exposure to Trichinella infection should be administratively organized, and more efficient and rigorous educational programs for both swine breeders and consumers (especially through the mass media) are imperative in order to prevent and eradicate trichinellosis in endemic areas. Implementation of strict hygienic measures aimed to control infection transmission are strongly recommended. When an acute infection is diagnosed, screening of family members and/or individuals who consumed the same infected meat products should be highly considered, in order to apply the preventive strategies and/or therapeutic actions.

\section{Acknowledgements}

Not applicable.

\section{Funding}

No funding was received.

\section{Availability of data and materials}

All data analyzed during this study are included in this published article.

\section{Authors' contributions}

MAL was responsible for the study design, implementation of the research, data collection, data analysis, and writing. RP was responsible for the study design, implementation of the research, data collection, data analysis, and writing. VEL was responsible for the data collection and implementation of the research. EDP conducted the data analysis, and epidemiological study. TRO was responsible for the study design, devised the project, verified the analytical methods, and helped supervise the project. All authors discussed the results, provided critical feedback and contributed to the final draft of the manuscript. All authors read and approved the final manuscript for publication.

\section{Ethics approval and consent to participate}

This study was approved by each of the infectious disease hospital's ethics committee: 'Victor Babes' Infectious Diseases Hospital Timisoara, Timis County; Infectious Disease Hospital Arad, Arad County; Municipal Hospital 'Doctor Alexandru Simionescu' Hunedoara, Hunedoara County.

\section{Patient consent for publication}

Not applicable.

\section{Competing interests}

The authors declare that they have no competing interests.

\section{References}

1. Rostami A, Gamble HR, Dupouy-Camet J, Khazan H and Bruschi F: Meat sources of infection for outbreaks of human trichinellosis. Food Microbiol 64: 65-71, 2017.

2. Foreyt WJ: Trichinosis. U.S. Geological Survey Circular 1388 Reston, Va, p60, 2013.

3. Gottstein B, Pozio E and Nöckler K: Epidemiology, diagnosis, treatment, and control of trichinellosis. Clin Microbiol Rev 22: $127-145,2009$

4. Capó V and Despommier DD: Clinical aspects of infection with Trichinella spp. Clin Microbiol Rev 9: 47-54, 1996.

5. Faber M, Schink S, Mayer-Scholl A, Ziesch C, Schönfelder R, Wichmann-Schauer H, Stark K and Nöckler K: Outbreak of trichinellosis due to wild boar meat and evaluation of the effectiveness of post exposure prophylaxis, Germany, 2013. Clin Infect Dis 60: e98-e104, 2015.

6. Dupouy-Camet J, Kociecka W, Bruschi F, Bolas-Fernandez F and Pozio E: Opinion on the diagnosis and treatment of human trichinellosis. Expert Opin Pharmacother 3: 1117-1130, 2002.

7. European Centre for Disease Prevention and Control (ECDC): Surveillance Atlas of Infectious Diseases. ECDC, Solna, 2018. http://atlas.ecdc.europa.eu/public/index. aspx?Instance $=$ GeneralAtlas. Accessed May 5, 2018.

8. Pavel R, Popovici ED and Olariu TR: Epidemiology of human trichinellosis in the European Union, 2007-2015. J Med Evol 23: No. 4, 2017.

9. Lupu MA, Lazureanu EV and Olariu TR: Trichinellosis in western Romania a 4 year retrospective study. Int J Infect Dis 53: 832016.

10. Dupouy-Camet J and Murrell KD (eds): FAO/WHO/OIE Guidelines for the surveillance, management, prevention and control of Trichinellosis. Food and Agriculture Organization of the United Nations, World Health Organization, World Organisation for Animal Health, 2007. http://www.fao.org/3/ a0227e/a0227e.pdf.

11. European Food Safety Authority and European Centre for Disease Prevention and Control: The European Union summary report on trends and sources of zoonoses, zoonotic agents and food-borne outbreaks in 2016. EFSA J 15: 5077, 2017.

12. PozioE,Ludovisi A,PezzottiP,BruschiFandGómez-Morales MÁ: Retrospective analysis of hospital discharge records for cases of trichinellosis does not allow evaluation of disease burden in Italy. Parasite 26: 42, 2019.

13. Neghina R, Neghina AM and Marincu I: Trichinellosis in hospitalized patients from a Romanian endemic area, 2007-2009. Clin Microbiol Infect 18: 86-90, 2012.

14. Neghina R, Neghina AM, Marincu I, Moldovan R and Iacobiciu I: Trichinellosis and poverty in a Romanian industrial area: An epidemiological study and brief review of literature. Foodborne Pathog Dis 7: 757-761, 2010.

15. Tatulescu DF, Muntean MI, Cismaru C, Astilean AE, Sabou MC and Crisan AM: An update on human trichinellosis in Romania-a 15 years retrospective study on the epidemiology and clinical signs. Sci Parasitol 11: 51-54, 2010. 
16. Blaga R, Durand B, Antoniu S, Gherman C, Cretu CM, Cozma V and Boireau P: A dramatic increase in the incidence of human trichinellosis in Romania over the past 25 years: Impact of political changes and regional food habits. Am J Trop Med Hyg 76: 983-986, 2007.

17. Borza C, Neghina AM, Dumitrascu V, Tirnea L, Calma CL and Neghina R: Epizootiology of trichinellosis in pigs and wild boars in Western Romania, 1998-2011. Vector Borne Zoonotic Dis 12: 712-713, 2012

18. Ruetsch C, Delaunay P, Armengaud A, Peloux-Petiot F, Dupouy-Camet J, Vallée I, Polack B, Boireau P and Marty P: Inadequate labeling of pork sausages prepared in Corsica causing a trichinellosis outbreak in France. Parasite 23: 27, 2016.
19. Murrell KD and Pozio E: Worldwide occurrence and impact of human trichinellosis, 1986-2009. Emerg Infect Dis 170: 2194-2202, 2011

This work is licensed under a Creative Commons Attribution-NonCommercial-NoDerivatives 4.0 International (CC BY-NC-ND 4.0) License. 